\title{
NEUROCIÊNCIA E OUTRAS MODULAÇÕES SUBJETIVAS EM EDUCAÇÃO: UM ESTUDO A PARTIR DA REVISTA NOVA ESCOLA
}

\author{
NEUROSCIENCE AND OTHERS SUBJECTIVE MODULATIONS IN EDUCATION: A \\ STUDY FROM NOVA ESCOLA MAGAZINE
}

\author{
Taís Kozlakowski Patrício \\ Mestra, Faculdade de Educação da Universidade de São Paulo - FEUSP \\ São Paulo, São Paulo - Brasil. \\ tkpatricio@gmail.com \\ (iD) Cintya Regina Ribeiro \\ Docente pesquisadora, Faculdade de Educação da Universidade de São Paulo - FEUSP \\ São Paulo, São Paulo - Brasil. \\ cintyaribeiro@usp.br
}

\begin{abstract}
Resumo: Focalizando a prevalência discursiva da neurociência na contemporaneidade, o artigo visa apreender os modos como os saberes pedagógicos, psicológicos, biológicos e neurológicos têm se articulado num âmbito específico da produção discursiva educacional brasileira atual, a fim de matizar seus efeitos nos processos de veridiç̧ão e constituição de subjetividades. Inspirando-se teórico-metodologicamente em Michel Foucault, toma como locus documental um conjunto de publicações da revista de divulgação pedagógica Nova Escola, no período de 2011 a 2016. A análise discursiva de enunciados aponta três principais aspectos: articulação entre corpo e subjetividade; atualização das discursividades de expertise nos processos de patologização e medicalização da vida; reconfiguração das políticas de cognição.
\end{abstract}

Palavras-chave: biopolítica; cognição; corpo; neurociência; subjetividade.

Abstract: Focusing on the prevalence of the neuroscientific discourse in contemporaneity, the article aims to apprehend the ways in which pedagogical, psychological, biological and neurological knowledge has been articulated in a specific field in the current Brazilian educational discursive production in order to qualify its effects into the constitutive processes of both veridiction and subjectivities. Theoretically and methodologically inspired on Michel Foucault, its source is a Nova Escolas's publications set, an educational dissemination magazine, published between 2011 and 2016. The statements discursive analysis shows three main aspects: the articulation between body and subjectivity; the updating of expertise discourses on the pathologization of life and medicalization processes; the reconfiguration of the cognition policies.

Keywords: biopolitics; body; cognition; neuroscience; subjectivation.

\section{Para citar - (ABNT NBR 6023:2018)}

PATRÍCIO, Taís Kozlakowski; RIBEIRO, Cintya Regina. Neurociência e outras modulações subjetivas em educação: um estudo a partir da revista Nova Escola. Eccos - Revista Científica, São Paulo, n. 58, p. 1-18, e10788, jul./set. 2021. Disponível em:

https://doi.org/10.5585/eccos.n58.10788. 


\section{Introdução}

Alegam Francisco Ortega (2008) e Nikolas Rose (2010, 2013) que, do advento da neurociência, termo inventado na década de 1960 para conjugar "o psicológico, o biofísico, o genético, o estatístico e toda uma série de disciplinas" (ROSE, 2010, p. 322), surgiu uma promessa: visualizar, estruturar e descrever neuroquimicamente o que se compreende por mente, pela noção de eu. Analisando discursivamente os saberes da neurociência, os autores afirmam que, para tal abordagem, as memórias, as opiniões, os prazeres, as dores e a totalidade do comportamento de um sujeito estariam inscritos e seriam produzidos em seu corpo e explicados não mais, ou não apenas, pela psicologia, mas por processos hormonais e nervosos passíveis de serem compreendidos a partir de estudos biológicos e neurológicos.

Outros campos do conhecimento, como a educação, têm sido implicados por tais saberes. O pesquisador português António Nóvoa (NÓVOA; VICHESSI; PORTILHO, 2012), em entrevista para a revista brasileira de divulgação pedagógica Nova Escola, ao ser questionado como resolveria a suposta "crise da educação", afirmou ter a sensação de déjà vu ao se deparar com trabalhos sobre educação e didática: "a Sociologia da Educação, a Psicologia da Infância e a piagetiana têm seu lugar, mas não ajudam a pensar de uma maneira inovadora a realidade pedagógica atual" (NÓVOA; VICHESSI; PORTILHO, 2012, s/p.). Ainda nessa entrevista, o autor sugere que a neurociência poderia enriquecer o trabalho de invenção de uma ciência da aprendizagem.

As possibilidades de articulação entre pedagogia e saberes biológicos, especialmente os da neurociência, têm sido pautas no debate educacional contemporâneo, expressando posicionamentos polêmicos. Mais especificamente, tal debate coloca em tensão discursiva quatro campos de saberes que, embora possam se imiscuir, territorializam e afirmam suas especificidades disciplinares. São eles: o pedagógico, o psicológico, o biológico e o neurológico.

Aliando-nos a uma análise inspirada no pensamento de Michel Foucault (2005, 2010a, 2010b, 2014, 2016), nosso objetivo é apreender os modos como tais saberes têm se articulado num âmbito específico da produção discursiva educacional brasileira na atualidade, tendo em vista matizar seus efeitos do ponto de vista dos processos de veridicção e de constituição de subjetividades.

Nesse intuito, apresentamos, em um primeiro momento, uma discussão teórica sobre a temática que é seguida pela análise empírica da pesquisa. Com o objetivo de apreendermos os modos de circulação discursiva entre tais saberes no presente, tomamos como locus documental 
um conjunto de publicações da já referida revista Nova Escola relativo ao período de 2011 a 2016. Tal escolha justifica-se uma vez que esse periódico constitui a maior publicação brasileira de divulgação referente à educação básica, contando com 1.624.440 leitores, de acordo com últimos dados divulgados no site da editora (PUBLIABRIL, 2013), condição que nos possibilita uma visibilidade estratégica dos modos de circulação desses saberes entre os profissionais da área educacional. Consultamos 46 edições na plataforma on line da editora, considerando ambas as modalidades: os volumes regulares de periodicidade mensal e os volumes de temáticas especiais.

A partir desse escopo, destacamos duas linhas de pensamento relativas às questões de subjetivação: de um lado, uma manifestação favorável à articulação desse novo saber neurobiológico ao campo psicológico-educacional; de outro, um posicionamento refratário perante tal articulação, em defesa de uma priorização de saberes da área de psicologia em detrimento do campo da neurobiologia no trato de certas problemáticas educacionais. É em meio a tais tensões discursivas que se configura e se acentua a presença contemporânea dessas três ciências, psicologia, biologia e neurociência, no campo pedagógico.

$\mathrm{Na}$ análise, apontamos que essas disputas discursivas, manifestas via Nova Escola, não se reduzem meramente à veiculação de sugestões de tendências contemporâneas em favor da melhoria da educação. Buscamos evidenciar criticamente as implicações dessas disputas nos processos de constituição de subjetividades mobilizados a partir dos jogos de verdade entre os referidos saberes.

\section{Subjetividades somatizadas}

A fim de contextualizarmos algumas proeminentes linhas de forças dessa discussão, vamos situar agora alguns marcadores teóricos. O médico neurologista português, António Damásio (2012) ficou mundialmente famoso por sua pesquisa no campo da neurociência. Preocupado em descrever cerebralmente nossa subjetividade, em seu primeiro livro de 1995, $O$ Erro de Descartes, o neurocientista afirmou que, ao longo dos três últimos séculos, compreender a fisiologia e a patologia do corpo era tarefa da biologia e da medicina, enquanto a mente era assunto apenas da religião, da filosofia e, posteriormente, da psicologia. Às ciências psicológicas tinha sido delegado estudar a mente; às ciências biológicas, em particular a medicina, era destinado apenas o estudo do corpo somático. Para ele, as relações entre subjetividade, cérebro, corpo e mente estavam reposicionadas: 
A emoção e os sentimentos constituem a base daquilo que os seres humanos têm descrito há milênios como alma ou espírito humano. [...] o corpo, tal como é representado no cérebro, pode constituir o quadro de referência indispensável para os processos neurais que experienciamos sendo a mente. O nosso próprio organismo, e não uma realidade externa absoluta, é utilizado como referência de base para as interpretações que fazemos do mundo que nos rodeia e para a construção do permanente sentido de subjetividade que é parte essencial de nossas experiências. De acordo com essa perspectiva, os nossos mais refinados pensamentos e as nossas melhores ações, as nossas maiores alegrias e as nossas mais profundas mágoas usam o corpo como instrumento de aferição. (DAMÁSIO, 2012, p. 20)

Surgiria, assim, uma espécie de "eu somático" que poderia ler o mundo a partir de si e que do seu interior poderia descrever a natureza. A mente, na concepção de Damásio, seria formada pelas aferições que o próprio corpo realiza e nele inscrita. Pensamentos, comportamentos e sentimentos residiriam em uma base orgânica, neurológica e efetivamente responsável pela formação da subjetividade. Mais do que aproximar a alma do corpo, agora, no interior desse tipo de enunciado, não haveria mais diferenciação entre eles.

Já o sociólogo inglês Nikolas Rose, por sua vez, dedicou-se a pensar as implicações dos modos como relacionamos nossas subjetividades ao corpo somático e biológico. Para ele, em decorrência das concepções que diferenciam mente e corpo, até a metade do século XX os sujeitos compreendiam-se como seres habitados por um profundo espaço psicológico interior. Entretanto, "aquele profundo espaço começou a nivelar-se, a ser deslocado - por um mapeamento direto da personalidade, e de suas doenças -, para o corpo ou para um cérebro" (ROSE, 2013, p. 44). As chamadas "ciências neuro" contribuíram para modificar as distâncias entre mente, corpo e subjetividade.

No entanto, o problema proposto por Damásio não era o mesmo de Rose. Enquanto Damásio dedicou-se a captar qual seria a real natureza da subjetividade humana, Rose, numa aproximação teórico-metodológica com Michel Foucault, problematizou como a neurociência poderia modificar nossos saberes e práticas, principalmente no que se refere à produção da verdade e dos modos de subjetivação: "Minha análise diz respeito não ao que os seres humanos são, mas ao que eles pensam que são [...] E, afirmo, estamos progressivamente chegando a nos relacionar a nós mesmos como indivíduos 'somáticos"” (ROSE, 2013, p. 44).

Nossa filiação com Foucault não seria, aqui, literalmente metodológica - tal qual Rose (2013) e, para lançar mão de seus próprios termos, não fizemos aqui, propriamente, uma genealogia, uma "história do presente", mas, sim, uma "cartografia mais modesta do nosso presente", com vistas à descrição de formas de vida emergentes. Portanto, a recusa à aderência imediata aos discursos do nosso próprio presente, desconsiderando-os como universais renúncia própria de um gesto foucaultiano (VEYNE, 2008) - norteou o nosso tratamento do 
arquivo empírico. Articulando a visão teórica de Foucault à de Rose e à de Francisco Ortega (2008), construímos um mapeamento do presente a partir dos discursos contemporâneos acerca de saberes biológicos, com um olhar acurado para os neurológicos, em circulação discursiva no campo da educação.

A problemática de Rose (2010) reside em um questionamento, se as neurociências fariam para o século XXI aquilo que as ciências psicológicas fizeram para o século XX: fornecer linguagens para compreendermos a nós mesmos e competências para nos gerenciarmos, de forma a podermos tornar nossos selves inteligíveis e, portanto, manipuláveis, permitindo a intervenção nos problemas constituídos nesse campo. A psicologia e a biologia conhecimentos que fundamentariam a neurociência - seriam, de acordo com o autor, parte da máquina de governança. Nessa prerrogativa, haveria um efeito de convergência dessas duas ciências - psi e bio - na medida em que ambas apontariam para o estabelecimento de certa subjetividade, para a criação de certa concepção de mente e de consciência. Para o autor, tais saberes se constituiriam como tecnologias de poder nos processos de subjetivação.

Essa perspectiva viabilizaria a concepção de subjetividades somáticas, si-mesmos biológicos (ROSE, 2013). Sistemas, órgãos, células, neurotransmissores, ligações químicas, sinapses e sinais elétricos seriam vistos como as bases da mente e do corpo, subjetivando os indivíduos em neurochemical selves, passíveis de se compreenderem como formados e governados por matéria neuroquímica (ROSE, 2004). Na mesma linha, Ortega (2008) nos interpela provocativamente sobre o modo como temos nos subjetivado em bioidentidades, questão que nos remete à exploração das implicações desse atual saber - a neurociência - nas tradicionais formas de conceber o homem.

A criação dessas novas práticas e saberes sobre a mente e o corpo conduz quem estiver no interior destas a outro estilo de pensamento (ROSE, 2013; ROSE; ABI-RACHED, 2013). Ao ser perpassado pela pergunta 'quem sou eu' e identificar-se com seu corpo para respondêla, o sujeito adentra esse modo de pensar-se a partir de uma subjetivação biológica. Dotado de propriedades químicas, físicas e biológicas, tal sujeito somático funda-se a partir de um vocabulário específico e passa a intitular seu corpo, seu cérebro, como 'eu', não como 'meu', assumindo-os como algo que está, de fato, a habitar sua mente - ela é o corpo, e vice-versa (ROSE, 2013). Pelo efeito da aderência a essas formas contemporâneas de subjetivação, a neurociência emerge como um saber biológico em destaque na nossa análise empírica.

Não é nosso objetivo conduzir uma exploração infinita acerca da busca de uma suposta verdade da condição subjetiva: se biológica ou psicológica. Alinhados ao pensamento de Michel Foucault $(2010 b$; 2005) deslocamos o eixo de problematização, reposicionando a 
pergunta: em vez de nos indagarmos sobre o estatuto do verdadeiro e do falso em relação à subjetividade, interessa-nos interrogar sobre os modos como nos inclinamos àquilo que compreendemos como sendo a verdade, ou seja, trata-se de apreender como uma verdade emerge como tal, tomando como premissa as disputas discursivas entre os saberes e seus modos de legitimação.

$\mathrm{Na}$ esteira foucaultiana, interrogamos o que faz com que se creia no verdadeiro, já que o conhecimento "além de não estar ligado à natureza humana [...] nem mesmo é aparentado, por um direito de origem, com o mundo a conhecer" (FOUCAULT, 2005, p. 17). Trata-se de problematizar o modo como tomamos por verdade algo que emerge na arbitrariedade de seu tempo.

Para Foucault (2014; 2005), herdeiro nietzschiano, não seríamos obrigados a crer no verdadeiro. Tampouco haveria uma vontade de verdade natural que nos mobilizaria a tal crença. Poderíamos, pois, abordar a problemática da verdade não mais em termos de obrigação, mas de autogoverno em relação às formas da verdade. Assim, nenhum sujeito contemporâneo se encontraria obrigado a subjetivar-se sob a forma de biodentidade; entretanto, essa discursividade bioidentitária tem acionado intensivamente modos de autogovernar-se e constituir-se como sujeito na contemporaneidade (ROSE 2004, 2010, 2013; ORTEGA, 2008).

Interessa-nos focalizar como se produz, ou não, uma psicologização somática; como se produzem, ou não, os biological e neurochemical selves, principalmente quando as especificidades dos saberes dos tipos bio e neuro se atravessam no campo da educação.

Uma das hipóteses sobre a prevalência da neurociência como um saber capaz de falar sobre a verdade das formas de subjetivação contemporâneas residiria na conexão representacional entre imagem e verdade. Rose (2010, 2013) e Ortega (2008) sustentam que, devido a uma concepção historicamente consolidada de que certos tipos de imagens seriam expressão da suposta positividade de um objeto, as tecnologias de imageamento do corpo seriam tomadas como mais científicas, portanto mais verdadeiras - do ponto de vista do modo científico de validação do verdadeiro. "A construção da verdade não passa mais pela palavra, e sim pela produção de imagens. Doravante, estabelece-se uma relação estreita entre o visual e o conhecimento científico do corpo humano" (ORTEGA, 2008, p. 99). Dessa associação entre imagem e realidade resultaria o caráter verídico das neurociências e da biologia, alicerçadas em tecnologias de imageamento. Tal crença também viabilizaria a inclinação, justificada cientificamente, às bioidentidades, cujo valor de verdade também se daria por meio da identificação de um corpo a uma imagem. "Agora parece que nós podemos ver as bases físicas 
da mente nas atividades do cérebro vivo. Ver é saber, e saber é ver" (ROSE; ABI-RACHED, 2013, nossa tradução).

Numa chave foucaultiana, diríamos que algo mais radical se faz nesse movimento de educação do olhar, ultrapassando um mero jogo de identificação: trata-se da própria experiência de criação de um corpo, corpo este que não existiria como um a priori a ser descoberto por uma ciência. Tal situação coloca sub judice também uma suposta natureza da condição subjetiva, uma vez que, de acordo com Foucault (2016, p. 13), “a subjetividade é concebida como o que se constitui e se transforma na relação que ela tem com a sua própria verdade. Não há teoria do sujeito independente da relação com a verdade".

Dessa forma, a contemporaneidade parece exigir um giro analítico crucial: em vez de nos determos numa suposta unidade de um sujeito ou de uma subjetividade, faz-se necessário deslocarmos o território do problema para a forma como os homens agem sobre os outros e sobre si mesmos. Isso remete à emergência da biopolítica na segunda metade do século XVIII, ou seja, às formas de poder sobre a vida e regulamentação da população, "como um problema a um só tempo científico e político, como um problema biológico e como um problema de poder" (FOUCAULT, 2010a, p. 206).

Para Rose (2010, 2013), a biopolítica do século XXI teria se modificado e os novos regimes de poder que atuam na subjetivação somática integram aquilo que se denomina política da própria vida, ou política da vida em si mesma. A responsabilidade sobre a vida, antes atribuída ao Estado, agora seria regulada por entidades praticamente autônomas; a política de vida, antes determinada pelo contraste entre a doença e a saúde, o normal e o anormal, agora se ocuparia, simplesmente, do melhoramento, do controle, da manipulação e da modulação (biológicos) da própria vida - cada vez mais precisos.

As tecnologias de imageamento configuram um corpo não mais molar - organizado sob a forma de sistemas - mas molecular, escalonado em razão de elementos de ordem micro. Com isso, privilegiam-se "as formas pelas quais tais elementos moleculares da vida podem ser mobilizados, controlados, aos quais se podem atribuir propriedades e podem ser combinados em processos que não existiam previamente" (ROSE, 2013, p. 30-31). É assim que toda a vida estaria implicada na política, afinal, afirmar "que a biologia não é destino, e dizer que algo é biológico é abrir-se à possibilidade de intervenção e transformação" (ROSE, 2010, p. 315).

Esse debate se impõe de forma inexorável: problematizar os processos de subjetivação ou os modos de constituição de subjetividades na contemporaneidade demanda deflagrar os efeitos da zona de tensão entre saberes psi, bio e neuro, apreendendo as formas como tais saberes se articulam e disputam os lugares de verdade, bem como os modos como nos 
implicamos nesses jogos, sobretudo na seara educacional. Adentrar tal território específico é nosso próximo alvo.

\section{Modulações subjetivas na revista Nova Escola}

A fim de flagrarmos o atravessamento da educação pelos saberes biológicos, especialmente os neurológicos, assim como as formas de subjetivação decorrentes desse encontro, selecionamos reportagens publicadas entre 2011 e 2016 na revista de divulgação educacional Nova Escola que se utilizaram de conhecimentos normalmente associados à biologia - da medicina, da psiquiatria, da neurociência - para discutir assuntos concernentes à educação. $\mathrm{Na}$ análise, foram inclusas reportagens tanto destinadas ao ensino desses conhecimentos quanto voltadas à sugestão de metodologias de ensino sustentadas por tais formas de saber. Considerando as produções das edições regulares e especiais, as matérias sugeridas nas edições on-line e os planos de aula, ao total foram selecionados 93 excertos para a análise.

Numa inspiração foucaultiana, procedemos à análise discursiva de enunciados buscando apreender a dinâmica das correlações dos saberes ali evocados com seus diagramas de forças, bem como os efeitos dessas configurações. Essa atenção analítica aos enunciados, em consonância com Foucault, Rose e Ortega, aponta para três principais modos de operação desses saberes, indicados nos seguintes eixos: 1) articulação entre corpo e subjetividade; 2) atualização das discursividades de expertise nos processos de patologização e medicalização da vida; 3) reconfiguração das políticas de cognição.

O primeiro eixo remete ao redimensionamento discursivo do corpo como vetor de subjetivação. Evidencia-se a incitação ao conhecimento do corpo como estratégia de produção de subjetividade. Denota-se também, nos registros selecionados, a presença de conhecimentos bio-neuro como um conteúdo a ser ensinado pelos professores e aprendido pelos alunos, em particular nas disciplinas de ciências e educação física. $\mathrm{O}$ autoconhecimento em relação ao corpo, com ênfase na autonomia e na gestão da saúde individual, opera como uma tecnologia de autogoverno que visa à produção de um modo de subjetivação.

Nessa linha, atentamos para enunciados que sugerem aos professores lecionarem sobre determinados conteúdos, tais como o funcionamento do corpo humano, por meio do uso de imagens, a fim de mostrar o interior do corpo. Presume-se que os alunos possam, a partir dessa visualização aliada ao aprendizado de um vocabulário de natureza biológica, criar compreensões sobre tais imagens bem como sobre o próprio funcionamento desse corpo. 
Destaca-se nessa chave a reportagem "Por que o nosso corpo para de funcionar?" (FERREIRA, 2012), na qual uma professora de $8^{\circ}$ ano do Ensino Fundamental relata sua experiência de ensino sobre a concepção biológica da morte. Para tanto, ela mostrou para os alunos uma série de representações do corpo humano, dentre as quais três tipos de tomografias cerebrais nas quais se visualizavam um cérebro considerado saudável, um com anomalias e um terceiro, inativo. Tais práticas pedagógicas se produzem a partir de modos neurobiológicos de subjetivação na medida em que se fomenta a constituição de uma espécie de eu-corpo, por meio de saberes bio e neuro que colocam em funcionamento outro modo de relação do sujeito consigo, viabilizando o jogo subjetivo de articulação entre corpo e identidade e constituindo aquilo que Ortega (2008) qualifica como subjetivação somática.

A forte injunção entre corpo e subjetividade marca presença nas discursividades analisadas. Num dos roteiros didáticos selecionados, intitulado "Corpo humano e saúde para $6^{\circ}, 7^{\circ}, 8^{\circ}$ e $9^{\circ}$ anos", a autora afirma que "o papel do professor é aproximar o aluno da informação correta sobre os hábitos que podem influenciar sua saúde" (CASTRO, s.d., s/p). Vale ressaltar, porém, que não se trata de um aprendizado de ordem meramente conteudística em relação a um saber de natureza bio ou neuro por parte de um aluno, tal como sugerido. Nessas propostas de ensino do corpo humano, encontra-se implicado um rol de procedimentos, entendidos como hábitos e práticas, que devem ser operacionalizados por parte dos estudantes para a condução de uma vida saudável. Trata-se de colocar em jogo uma dimensão da ordem da conduta.

Assim, notamos, nos registros da Nova Escola analisados, o privilégio de um modo discursivo que articula um tipo de saber a uma norma de conduta, ativado sob a rubrica da autonomia. Postula-se a necessidade de se conhecer o corpo humano (biologicamente) para que o estudante desenvolva a autonomia necessária a fim de gerir os cuidados com a sua saúde. Essa operação somente se efetiva sob a forma de autogoverno, ou seja, por meio de um voltar-se sobre si mesmo, a partir do estabelecimento de certos modos específicos de relação consigo, com vistas a atuar nos jogos de normalização em favor da gestão política da vida.

Tal prerrogativa do autogoverno se explicita, do ponto de vista pedagógico, em termos de autonomia e responsabilidade individuais. Na matéria "Circuitos para pensar sobre o corpo em movimento", a ênfase do lugar do corpo como ocasião dessa operação de reflexividade da conduta se faz nuclear: "você precisa levar cada estudante, logo no início da escolaridade, a se observar e se analisar" (VICHESSI; SCAPATICIO, 2011, s/p.).

A premissa do autoconhecimento derivado da experiência corporal e suas implicações na construção das subjetividades também é ativada nas matérias "O ano em que pifei - e o que 
aprendi com isso" (RATIER, 2016) e "Burnout. Depressão. Ansiedade. Como desatar esses nós" (RATIER; CASSIMIRO; PADIAL, 2016). Ambas matérias estabelecem como norma de conduta essa incitação reflexiva para conhecer o corpo, as emoções e sensações em favor da produção de um modo de subjetividade e, mais amplamente, da própria vida.

O segundo eixo destacado da análise dos enunciados da Nova Escola remete à atualização das discursividades de expertise nos processos de patologização e medicalização da vida. Aqui, identificamos as mais calorosas discussões quanto aos usos dos saberes bio-neuro no campo educacional relacionados ao cuidado para com a saúde dos alunos. Nestas reportagens indica-se a procura de profissionais da medicina, da biologia ou da neurologia para que estes realizem diagnósticos de síndromes, deficiências e patologias nos estudantes, bem como definam suas formas de cuidado.

Dentre algumas sugestões de medidas a serem tomadas a partir do uso dos saberes bioneuro encontram-se: a) a busca por um psiquiatra para tratar a comunidade escolar que viveu o chamado massacre de Realengo ${ }^{1}$ - na matéria "O desafio de seguir em frente" (MOÇO, 2012); b) o encaminhamento de adolescentes grávidas a ginecologistas - na matéria "Uma aluna de 13 anos veio me contar que acha que está grávida. O que fazer?" (VINHA, 2013); c) o encaminhamento de crianças a um médico no caso de emergência na escola - "O que fazer em casos de emergência na escola?” (RAMOS, 2012a); d) o tratamento da gagueira dos professores com um fonoaudiólogo - "Quando fico nervosa, começo a gaguejar. Isso pode ser um empecilho para dar aula?" (RAMOS, 2012); e) a correção de postura com um fisioterapeuta "Mantenha a postura" (CAMILO, 2013); f) a procura por médicos para diagnosticar e tratar Transtornos de Déficit de Atenção (TDAH) ou dislexia - em diversas matérias como "O que é transtorno de déficit de atenção com ou sem hiperatividade (TDAH)" (BIBIANO, 2010), "Três mitos da dislexia” (PINTO, 2008); “Como fica a questão da saúde na escola?”, (MENEZES, 2011); g) a procura por vários tipos de especialistas para lidar com o autismo em "A inclusão de estudantes autistas" (WINKEL, 2014).

Esse tipo de abordagem já não focalizaria uma ordem preventiva, baseada no autoconhecimento corporal, por parte dos alunos. Aqui, convoca-se a presença dos experts para a atuação junto aos profissionais da área de educação, denotando, assim, os limites do campo educacional stricto sensu no enfrentamento de certas questões. A esse respeito, a afirmação de uma psicopedagoga (MANTOVANINI; VICHESSI, 2012), em entrevista publicada numa das edições de Nova Escola, é exemplar:

${ }^{1}$ Refere-se ao caso de 2007, quando um ex-aluno entrou na sua antiga escola no Rio de Janeiro, no bairro de Realengo, armado, matando a tiros 12 crianças. (MOÇO, 2012) 
De qualquer maneira, educadores e psicopedagogos não estão aptos a diagnosticar dislexia, hiperatividade ou outro distúrbio desse tipo. É antiético e irresponsável dizer à família: "Seu filho é disléxico". Só quem pode afirmar isso são os médicos (s/p).

Testemunhamos um espectro de problemas que atingiriam a escola e que não poderiam ser resolvidos pelas credenciais dos especialistas da área da educação - e nem mesmo da psicologia - situação que tem suscitado muitos debates atuais, principalmente no que tange ao incremento e às novas formulações das práticas de patologização e medicalização dos discentes. Tal expertise extraescolar tem sua força de atuação na cientificidade dos saberes biológicos, agora atualizados e potencializados pelas investigações no âmbito da neurociência.

A exterioridade desses saberes bio, neuro e psi, quando acionada na interioridade do campo educacional, gera tensões advindas dessas zonas de fronteiras e produzem impactos nos modos de produção de subjetividades. No limite, tais saberes competem pela legitimidade da verdade de seus objetos. Aquilo que está em jogo parece ser a disputa tanto pela ocupação discursiva do ato educacional - e, mais especificamente, do ato pedagógico - quanto pela definição de quem é o sujeito da educação, ou seja, de qual é a verdade dessa subjetividade talhada no campo educacional.

Na entrevista já citada, Mantovanini (2012) defende que muitos problemas educacionais que supostamente seriam sintomas de transtornos, poderiam ser resolvidos com tecnologias da educação - outros modos de apresentação do conteúdo, de organização do tempo e espaço, de flexibilização das fases de aprendizagem etc. Essa posição é paradigmática e singulariza esse jogo de saberes em fronteiras: ao mesmo tempo em que se reconhece e se valora a legitimidade dos diversos campos disciplinares no trato com seus problemas específicos, também se afirma a soberania do saber pedagógico no campo educacional.

Tal postura argumentativa que valora uma conduta pedagógica e/ou psicológica em detrimento de uma ação com base biológica e neurobiológica se reproduz em muitas matérias produzidas pela Nova Escola, entre as quais - "Ritalina, a escola esqueceu que é melhor prevenir do que remediar" (FERREIRA, 2013) e "Três mitos da dislexia" (PINTO, 2008).

Dessa forma, em relação à atualização da expertise sobre patologização e medicalização da vida, a análise dos materiais publicados pela Nova Escola explicita disputas entre saberes psicológicos e pedagógicos de um lado e saberes biológicos e neurocientíficos do outro. Se, algumas vezes, observamos convergências entre tais forças, outras vezes, nos deparamos com seus movimentos divergentes, sinalizando resistências de ordem discursiva. Os arranjos e embates descritos evidenciam um terceiro eixo de nossa análise: a reconfiguração das políticas de cognição. 
Aqui, os materiais discursivamente analisados denotam um esforço de relacionar em que medida as supostas condições de saúde e doença implicam o processo pedagógico, isto é, a operação cognitiva efetuada na relação de ensino e aprendizagem. Do ponto de vista das políticas de cognição, esses materiais analisados apontam que o debate sobre patologização e medicalização tem como alvo discutir o quanto uma ação pedagógica transfere suas problemáticas para campos de saberes que lhe são exteriores e que são legitimados sob a autoridade da voz de um especialista alheio ao campo educacional, stricto sensu. O que está em jogo é, portanto, a necessidade de gestão da cognição bem como da avaliação acerca de quais seriam os saberes autorizados para enfrentar tal problemática, em favor de um melhoramento cognitivo dos discentes.

Ora, como afirma Rose (2010, 2013), uma compreensão neurobiológica do homem possibilitaria um aprimoramento da subjetivação biológica. Para o autor, o sujeito somático do século XXI perseguiria não um modelo único de homem - situado na chave normativa da saúde versus patologia - mas uma forma de vida pautada na otimização, na demanda por aperfeiçoamento regida por vontades específicas e individuais - eis a força biopolítica que amalgamaria educação e neurociência.

Aqui, os saberes da neurociência em jogo com saberes psicológicos e pedagógicos tendem a ser valorados por possibilitarem a reconfiguração das políticas de cognição, uma vez que auxiliariam na compreensão de processos cognitivos afeitos ao ensino e à aprendizagem. Essa correlação é evidenciada por Nóvoa (NÓVOA; VICHESSI; PORTILHO, 2012, s/p):

[...] continuamos pensando a Pedagogia como antes. Temos de fazer outra revolução. Cabe à escola caminhar para tornar mais complexas as dimensões do conhecimento e da comunicação. Necessitamos inventar a ciência da aprendizagem - enriquecida com a Neurociência -, da comunicação e da gestão da aprendizagem.

Defende-se, assim, que o uso de teorizações de natureza bio-neuro no campo educacional possa atuar de forma análoga às psicologias do desenvolvimento, seja fundamentando metodologias de ensino, seja comprovando sua eficácia, seja inspirando novas formas de atuação docente.

De modo ressoante, a Nova Escola publicou em sua matéria de capa o tema "Neurociência: como ela ajuda a entender a aprendizagem", da qual destacamos: 
Sabemos, por exemplo, com base em evidências neurocientíficas, que há uma correlação entre um ambiente rico e o aumento das sinapses (conexões entre as células cerebrais). Mas quem define o que é um meio estimulante para cada tipo de aprendizado? Quais devem ser as intervenções para intensificar o efeito do meio? Como o aluno irá reagir? "A Neurociência não fornece estratégias de ensino. Isso é trabalho da Pedagogia, por meio das didáticas", diz Hamilton Haddad [...]. Como, então, o professor pode enriquecer o processo de ensino e aprendizagem usando as contribuições da Neurociência? (SALLA, 2012a, s/p)

Evidencia-se, a partir da prevalência de um jogo cientificista, a defesa dessa aliança entre neurociência e pedagogia no intuito de resolução de questões de ensino e aprendizagem. Após apresentar um problema educacional sob a perspectiva da neurociência - como fazer com que a emoção, a motivação, a atenção, o conceito de plasticidade cerebral e a memória auxiliem a aprendizagem? - e expor ideias dos psicólogos do desenvolvimento - Piaget, Vygotsky, Wallon, Ausubel -, a autora propõe como a área da educação poderia pensar em soluções práticas para resolvê-los. Explicita-se, pois, como as raízes bio, neuro, psi e pedago operam em conjunção como tecnologias discursivas visando à melhoria do desenvolvimento cognitivo dos alunos, por meio de práticas cientificamente orientadas.

Nessa mesma direção valorativa, a matéria "Esta escrita vai desaparecer?", sobre o recente desuso da letra cursiva (HAMINE; SOARES; ANNUNCIATO, 2016), também evoca a produtividade entre os saberes da neurociência e o desenvolvimento cognitivo, com foco na escrita, a partir de certa compreensão do funcionamento cerebral. A discussão sobre a ênfase nas dimensões biológica e neurológica do cérebro humano também encontra ecos na matéria “Os desafios da segunda plasticidade cerebral" (MACEDO, 2016), na qual o conceito de plasticidade cerebral é evocado a partir do pensamento piagetiano.

Essa presença dos saberes da biologia e da neurociência, porém, não é algo bem equacionado no campo educacional. Na matéria "Você sabe o que são neuromitos?" Salla (2012b) alerta ainda para a condição da neurociência como campo emergente e, portanto, para o risco da adesão educacional a pressupostos ainda não validados cientificamente, os quais se constituiriam, antes, como mitos e especulações.

Valendo-se de uma discursividade cientificista, a autora destaca cinco casos nos quais se incorreria em tais enganos. Um desses neuromitos refere-se à afirmação de que haveria fases, períodos da vida, para cada aprendizagem, que se tornaria inviável fora desse momento ideal. Inicialmente, a autora apresenta uma pesquisa que, a despeito de ter sido realizada por métodos científicos, teria induzido a esse "erro". Em seguida, descreve o experimento neurocientífico que comprovaria o equívoco da referida tese, trazendo, em contrapartida, o conceito de plasticidade cerebral, característica que permitiria considerar o aprendizado como passível em qualquer fase da vida. 
Tal conceito modificaria as relações de governo das subjetividades biológicas, pois permitiria conceber o cérebro não mais como condição do destino, numa pressuposição de que suas funções permaneceriam as mesmas ao longo da vida. Tomando-o, agora, como extremamente flexível e maleável, o cérebro estaria disponível para modificar-se, mudar suas relações. A esse respeito, Rose e Abi-Rached demarcam sua perspectiva crítica:

\footnotetext{
As implicações são claras: aqueles que se preocupam com o futuro de suas crianças, e com a condução e bem-estar dos adultos que irão se tornar, precisam reconhecer, e governar, esses processos de formação e reformação do nosso cérebro plástico. (ROSE; ABI-RACHED, 2013, p. 12, tradução nossa)
}

Segundo essa visão, haveria sempre uma forma de interferir no cérebro, na mente e, como consequência, na própria condição de subjetividade, possibilitando a otimização da aprendizagem em qualquer etapa da vida. Por essa razão, argumentamos que tais prerrogativas permitiriam a reconfiguração das políticas de cognição não só na esfera eminentemente escolar, mas em todos os domínios experienciais da vida social.

\section{Considerações finais}

As análises apontam para certos modos como são estabelecidos os jogos de verdade entre as práticas da biologia, da neurociência, da psicologia e da pedagogia. Especificamente, poderíamos perceber conjunções e disjunções entre discursividades psicopedagógicas e neurobiológicas, uma vez que os saberes pedagógicos e psicológicos tendem a se combinar como um vetor de força, da mesma forma que os saberes da biologia e da neurociência tendem a se combinar como outro.

Vale destacar que, a despeito da forte presença das forças discursivas neurobiológicas no campo psicopedagógico, tal agenciamento não se faz de modo unívoco. A análise dos modos por meio dos quais essas tensões se desenham no campo educacional permite-nos formular algumas considerações.

Deparamo-nos com o acento contemporâneo do imperativo cientificista no campo educacional, em suas várias modulações. Observamos que, embora a presença da discursividade neurobiológica não seja consensual na área da educação, tal razão não se dá por uma problematização dos modos de produção de verdade científica dos saberes bio e neuro, ou seja, não estão em causa os dispositivos científicos de produção das verdades. Essa ausência de consenso se dá por uma questão de ordem valorativa, isto é, ela diz respeito aos critérios de avaliação do grau de legitimidade dessa presença. Isso se expressa claramente, pois nas matérias analisadas não se nota a discussão sobre o estatuto dos saberes científicos como lugar de 
verdade na vida contemporânea; nota-se, sim, somente o embate sobre o grau de presença desejável desses modos científicos na conversação com os problemas do nosso campo. Tal situação se apresenta em razão das ambiguidades presentes nas relações entre a área da educação e os campos científicos de expertise que lhe são estrangeiros.

Essas outras modulações do imperativo cientificista produzem efeitos nos processos de subjetivação, de constituição de subjetividades. Seja o sujeito pedagógico tomado como ser psicológico, ser somático ser neurobiológico, ser plástico-cerebral etc., evidencia-se, nos fundamentos das matérias analisadas da Nova Escola, a figura soberana do ser sujeito como lastro e referência da ação educativa - no limite, trata-se de educar um sujeito, de localizar uma subjetividade, de investi-la.

Essa prevalência da categoria do sujeito da educação nas matérias tecidas no cruzamento de saberes bio, neuro, psi e pedago não se restringe à dimensão do aluno, mas afeta também a do professor, em dupla articulação. Com isso, a Nova Escola, como mídia de divulgação científica, opera efetivamente como tecnologia discursiva nos processos de subjetivação ou na produção de subjetividades de modo extensivo a todos os implicados no processo pedagógico. Por um lado, as matérias dispõem em circulação discursiva propostas de ensino que, forjadas no cruzamento desses quatro saberes citados, podem ser mobilizadas pelo professor no sentido de formar um aluno, um sujeito educacional em condição de gestão da própria vida. Porém, nessa operação, tais matérias também colocam em circulação discursiva a figura ideal de um professor em processo de aprendizagem contínua dos saberes em voga num determinado tempo histórico, saberes estes que estão sendo selecionados, valorados e ensinados aos professores, via revista, por meio de vozes de expertise.

Poderíamos afirmar que se trata de um efeito de reconfiguração generalizada de políticas de cognição, seja do ponto de vista da educação de alunos ou da formação continuada de professores. Trata-se, pois, de um espraiamento da gestão da cognição, num alvo duplo: alunos e professores.

Mais do que o domínio de um tipo de conhecimento que, então, qualificamos como neurobiológico, essa produção analisada não atua simplesmente como veículo de divulgação científica, mas - tomada ela mesma como uma tecnologia discursiva - faz funcionar um modo de operação corpo-mente, configurando, assim, aquilo mesmo que, do ponto de vista de uma mirada foucaultiana, podemos chamar de processos de subjetivação e seus efeitos de produção de subjetividades.

Tais considerações nos lançam a outro horizonte crítico. Não se trata de discutir o estatuto de verdade ou falsidade de um tipo de sujeito ou de uma educação forjada na tensa 
composição entre esses saberes. A nosso ver, essa exploração analítica dos matizes da circulação discursiva no campo educacional atual permite-nos apreender os efeitos desse modo de educação, isto é, dessas modulações subjetivas, tanto discentes quanto docentes.

Atentar para a singularidade e a atualidade dessas forças, deflagrando os modos como esses saberes se agenciam na contemporaneidade, nos possibilita o enfrentamento de uma interrogação mais aguda, de cunho filosófico, a qual remete, no limite, à problematização ética da própria política da vida - eis uma questão crítica de primeira grandeza, sobretudo quando nos encontramos inarredavelmente implicados no território educacional e nos alinhamos com um compromisso frente à diversidade dos modos de existência que, na atualidade, marcam presença e abrem passagem.

\section{Referências}

BIBIANO, Bianca. O que é o Transtorno de Déficit de Atenção com ou sem Hiperatividade (TDAH). Nova Escola (on line). abril 2010. Disponível em:

https://novaescola.org.br/conteudo/292/transtorno-deficit-atencao-com-sem-hiperatividadetdah. Acesso em 13. abr. 2019.

CAMILO,Camila. Mantenha a postura. Nova Escola (on line). março 2013. Disponível em: https://novaescola.org.br/conteudo/3441/mantenha-a-postura. Acesso em 13. abr. 2019.

CASTRO, J. Corpo humano e saúde para $6^{\circ}, 7^{\circ}, 8^{\circ}$ e $9^{\circ}$ anos. Nova Escola (on line), s.d. Disponível em: http://revistaescola.abril.com.br/fundamental-2/roteiro-didatico-corpohumano-saude-6-7-8-9-anos-642782.shtml?page=3.3. Acesso em 5. ago. 2013.

DAMÁSIO, António R. O Erro de Descartes. 3. ed. São Paulo: Companhia das Letras, 2012.

FERREIRA, Anna. Por que nosso corpo para de funcionar? Nova Escola (on line). dez 2012. Disponível em: https://novaescola.org.br/conteudo/2190/por-que-nosso-corpo-para-defuncionar. Acesso em 13. abr. 2019.

FERREIRA, Anna. Ritalina: a escola esqueceu que é melhor prevenir do que remediar. Nova Escola (on live). junho 2013. Disponível em:

https://novaescola.org.br/conteudo/1897/ritalina-a-escola-esqueceu-que-e-melhor-prevenirdo-que-remediar. Acesso em 13. abr. 2019.

FOUCAULT, Michel. Aula de 17 de março de 1976. In: Em defesa da sociedade. 2. ed. São Paulo: Martins Fontes, 2010a, p. 285-315.

FOUCAULT, Michel. Aula de 5 de janeiro de 1983: primeira hora e segunda hora. In: $O$ Governo de si e dos outros: curso no Collège de France. São Paulo: WMF Martins Fontes, 2010b, p. 3-29.

FOUCAULT, Michel. Do governo dos Vivos. 1. ed. São Paulo: Martins Fontes, 2014. 
FOUCAULT, Michel. A verdade e as formas jurídicas. 3. ed. Rio de Janeiro: Editora Nau, 2005, p. 7-27.

FOUCAULT, Michel. Subjetividade e verdade. 1. ed. São Paulo: Martins Fontes, 2016.

HAMINE, Jacqueline; SOARES, Wellington; ANNUNCIATO, Pedro. Esta escrita vai desaparecer?. Nova Escola (on line). novembro 2016. Disponível em:

https://novaescola.org.br/conteudo/8710/esta-escrita-vai-desaparecer. Acesso em 13. abr. 2019.

MACEDO, Lino de. Os desafios da segunda plasticidade cerebral. Nova Escola (on line). setembro 2016. Disponível em: https://novaescola.org.br/conteudo/8672/os-desafios-dasegunda-plasticidade-cerebral. Acesso em 13. abr. 2019.

MANTOVANINI, Maria; VICHESSI, Beatriz. Entrevista com Maria Cristina Mantovanini. Nova Escola (on line). ed. 253, junho/julho 2012. Disponível em:

https://novaescola.org.br/conteudo/886/entrevista-com-maria-cristina-mantovanini. Acesso em 14. jan. 2018.

MENEZES, Luis. Como fica a questão da saúde na escola?. Nova Escola (on line). abril 2011. Disponível em: https://novaescola.org.br/conteudo/638/como-fica-a-questao-da-saude-naescola. Acesso em 13. abr. 2019.

MOÇO, Anderson. EM Tasso da Silveira: o desafio de seguir em frente. Nova Escola (on line). maio, 2011. Disponível em: https://novaescola.org.br/conteudo/1927/em-tasso-dasilveira-o-desafio-de-seguir-em-frente. Acesso em 13. abr. 2019.

NÓVOA, António; VICHESSI, Beatriz; PORTILHO, G. Entrevista com o educador português António Nóvoa. Nova Escola (on line), ed. 256, outubro 2012. Disponível em: https://novaescola.org.br/conteudo/212/entrevista-educador-portugues-antonio-novoa. Acesso em 14. jan. 2018.

ORTEGA, Francisco. O Corpo Incerto. Rio de Janeiro: Garamond, 2008.

RAMOS, Heloisa. O que fazer em caso de emergência na escola?. Nova Escola (on line). junho 2012a. Disponível em: https://novaescola.org.br/conteudo/719/o-que-fazer-em-caso-deemergencia-na-escola. Acesso em 13. abr. 2019.

RAMOS, Heloisa. Quando fico nervosa, começo a gaguejar. Isso pode ser um empecilho para dar aula?. Nova Escola (on line). Abril 2012b. Disponível em:

https://novaescola.org.br/conteudo/1864/quando-fico-nervosa-comeco-a-gaguejar-isso-podeser-um-empecilho-para-dar-aula. Acesso em 13. abr. 2019.

RATIER, Rodrigo. O ano em que pifei e o que aprendi com isso. Nova Escola (on line). outubro 2016. Disponível em: https://novaescola.org.br/conteudo/8685/o-ano-em-que-pifei-e-o-que-aprendi-com-isso. Acesso em 13.abr. 2019.

RATIER, Rodrigo; CASSIMIRO, Patrick; PADIAL; Karina. Burnout. Depressão. Ansiedade. Como desatar esses nós. Nova Escola (on line). novembro 2016. Disponível em: 
https://novaescola.org.br/conteudo/8701/burnout-depressao-ansiedade-como-desatar-essesnos. Acesso em 13. abr. 2019.

ROSE, Nikolas. Becoming Neurochemical Selves. In: STEHR, Nico (ed.) Biotechnology, Commerce And Civil Society, Somerset, Transaction Publishers, p. 89-128, jan. 2004.

ROSE, Nikolas. Cérebro, self e sociedade: uma conversa com Nikolas Rose. (Entrevista). Physis Revista de Saúde Coletiva, Rio de Janeiro, v. 1, n. 29, p. 301-324, 2010.

ROSE, Nikolas. A Política da Própria Vida. 1. ed. São Paulo: Editora Paulus, 2013.

ROSE, Nikolas; ABI-RACHED, Joelle M. Neuro. New Jersey: Princeton University Press, 2013.

SALLA, Fernanda. Neurociência: como ela ajuda a entender a aprendizagem. Nova Escola (on line). ed. 253, junho/julho 2012a. Disponível em:

https://novaescola.org.br/conteudo/217/neurociencia-aprendizagem. Acesso em 14. jan. 2018.

SALLA, Fernanda. Você sabe o que são neuromitos?. Nova Escola (on line). maio 2012b. Disponível em: https://novaescola.org.br/conteudo/1970/voce-sabe-o-que-sao-os-neuromitos. Acesso em 14. jan. 2018.

PINTO, Deca. Três mitos da dislexia. Nova Escola (on line). fevereiro 2008. Disponível em: https://novaescola.org.br/conteudo/1344/quatro-mitos-da-dislexia. Acesso em 13. abr. 2019.

PUBLIABRIL. Informações sobre a revista Nova Escola. s.d. Disponível em:

http://www.publiabril.com.br/marcas/novaescola/revista/informacoes-gerais. Acesso em: 5. ago. 2013.

VEYNE, Paul. Foucault, o pensamento, a pessoa. 1. ed. Lisboa: Edições texto e grafia, 2009.

VICHESSI, Beatriz; SCAPATICIO, M. Circuitos para pensar sobre o corpo em movimento. Nova Escola (on line). ed. 245, setembro 2011. Disponível em:

https://novaescola.org.br/conteudo/1996/circuitos-para-pensar-sobre-o-corpo-em-movimento. Acesso em: 14. jan. 2018.

VINHA, Telma. Uma aluna de 13 anos veio me contar que acha que está grávida. O que fazer?. Nova Escola (on line). março 2013. Disponível em:

https://novaescola.org.br/conteudo/593/uma-aluna-de-13-anos-veio-me-contar-que-acha-queesta-gravida-o-que-fazer. Acesso em 13. abr. 2019.

WINKEL, Sophia. A inclusão de estudantes autistas. Nova Escola (on line). dezembro 2014. Disponível em: https://novaescola.org.br/conteudo/3439/a-inclusao-de-estudantes-autistas. Acesso em: 13. abr. 2019. 